EGU2020-19308

https://doi.org/10.5194/egusphere-egu2020-19308

EGU General Assembly 2020

(c) Author(s) 2021. This work is distributed under

the Creative Commons Attribution 4.0 License.

\title{
Electromagnetic experiments for the detection and characterization of seafloor massive sulfides: two case studies from the Mediterranean and Northern Mid-Atlantic Ridge
}

Hölz Sebastian, Haroon Amir, Konstantin Reeck, and Jegen Marion

GEOMAR - Helmholtz Centre for Ocean Research Kiel, Germany, (shoelz@geomar.de)

Seafloor massive sulfides (SMS) are regarded as a potential future resource to satisfy the growing global demand of strategic metals. Aside from mining and retrieving profitable amounts of massive sulfides from the seafloor, the present challenge is to detect and delineate significant SMS accumulations, which are generally located near mid-ocean ridges and along submarine volcanic arc and backarc spreading centers.

In the past years we have used the marine transient electromagnetic induction system MARTEMIS, a coincident-loop TEM system developed at GEOMAR (Kiel, Germany), in various marine geological settings for the detection and characterization of SMS in the shallow seafloor down to a depth of $\sim 30 \mathrm{~m}$. The system was also used in combination with remote EM receivers (Coil2Dipole experiment) to allow for investigations of conductive structures, which are covered by up to $\sim 100 \mathrm{~m}$ of sediments.

We present experiments from two locations, one at an inactive site in the Mediterranean (Palinuro, Tyrrhenian Sea) where the occurrence of SMS had previously been confirmed by drilling, and one active site on the Northern Mid-Atlantic Ridge (Grimsey Hydrothermal Field, offshore Northern Iceland) where no SMS have been found in gravity cores up to now. The results demonstrate the suitability of the system to detect, delineate and characterize SMS even in scenarios, where the mineralizations are no longer connected to any hydrothermal activity or are buried under a sedimentary cover. 